\title{
Crypts With Corrupted Shapes in Non-polypoid Adenomas
}

\author{
CARLOS A. RUBIO ${ }^{1}$ and PETER T. SCHMIDT ${ }^{2}$ \\ ${ }^{1}$ Gastrointestinal and Liver Research Laboratory, Department of Pathology, \\ Karolinska Institute and University Hospital, Stockholm, Sweden; \\ ${ }^{2}$ Department of Medicine Solna, Center for Digestive Diseases, \\ Karolinska Institute and University Hospital, Stockholm, Sweden
}

\begin{abstract}
Background: Colonic crypts with normal epithelial lining exhibiting corrupted shapes (NECS) have been previously found beneath the adenomatous tissue of polypoid conventional adenomas, in both rats and humans. Aim: To assess the frequency of NECS in non-polypoid colonic flat adenomas (FAs) and lateral-spreading adenomas (LSAs). Materials and Methods: Histological hematoxylin and eosin-stained sections from 51 non-polypoid colonic adenomas were scrutinized over a 10-mm field of vision $(F O V)$. FAs were regarded lesions encompassed within the FOV and LSAs as those surpassing that limit. The NECS/mm ratio was calculated in individual lesions as the number of NECS beneath the adenomatous tissue, divided by the length (mm) of the FA and LSA. Results: Out of the 51 non-polypoid adenomas, 27 were FAs and the remaining 24 LSAs. All 51 non-polypoid lesions were tubular adenomas. The mean number of NECS in FAs was 6.29 (range=2-10) and in LSAs was 15.29 (range $=7-41)(p<0.05)$. On the other hand, the mean NECS $/ \mathrm{mm}$ ratio in FAs was 0.94 (range $=0.50-2.00$ ) and in LSAs was 0.92 (range $=0.40-2.93$ ). Thus, no essential differences in the number of NECS/mm was found between FA and LSA. Conclusion: The accretion of NECS below the neoplastic canopy of FA and LSA contrasts with the rare occurrence of NECS in normal colonic mucosa. This finding emerges as a previously unaddressed major event, an event that might play an important role in the histogenesis of nonpolypoid adenomas of the colon.
\end{abstract}

In the past decades, the improvement of endoscopic optical devices supplemented with mucosal dyes (chromoendoscopy)

Correspondence to: Carlos A. Rubio, MD, Ph.D., Gastrointestinal and Liver Pathology Research Laboratory, Department of Pathology, Karolinska Institute and University Hospital, 17176, Stockholm, Sweden. Tel: +46 851774527, Fax: +46 851774524, e-mail: Carlos.Rubio@ki.se

Key Words: Colon, crypts, distortions, flat adenomas, lateralspreading adenomas. has permitted colonoscopists to visualize previously concealed mucosal lesions. In 1985, Muto and colleagues found 14 small nonpolypoid mucosal lesions measuring not more than $1 \mathrm{~cm}$ in diameter at colonoscopy in humans (1). Since the histological examination revealed adenomas, those lesions were called "flat" adenomas (FA).

In 1995, in a clinical study, Jaramillo et al. detected 109 flat neoplastic lesions with the aid of high-resolution video colonoscopy with chromoscopy: 97\% were FAs and 3\% FAs with submucosal invasion (2). In another clinical study, adenomas were found in $92 \%$ out of 208 flat lesions (3). In a comparative survey of 781 flat colorectal neoplasias collected at the Karolinska Hospital, Stockholm, Sweden, and at the four main Hospitals in Tokyo, Japan (4), we found high-grade dysplasia in $42 \%$ out of 420 FAs in Japanese patients but only 14\% out of 361 FAs in Swedish patients. Intramucosal and submucosal carcinoma occurred in $15 \%$ of the flat neoplasias from Japan, but only in $3 \%$ of those seen in Sweden. Thus, FAs were more advanced in Japan (in terms of high-grade dysplasia) and more aggressive (in terms of intramucosal and submucosal invasion) than in Sweden (4). Those findings underpinned controversies regarding histological differences between flat colonic neoplasias in Japan and in Western countries $(5,6)$. Lately, the histological differences between Western and Japanese regarding the classification of gastrointestinal epithelial neoplasias were largely resolved by adopting the Vienna classification $(7,8)$.

In 1997, Kudo et al. called laterally-spreading tumors (LSTs) those nonpolypoid neoplasms of large size, with a lateral diameter greater than $10 \mathrm{~mm}$ (9). In subsequent surveys, adenomas were found in $85 \%$ out of 497 LSTs (10), in $88 \%$ out of 239 LSTs (11), and in all (100\%) 33 LSTs investigated (12). Apparently, adenomas account for the majority of FAs and LSTs in the literature.

It remains unclear as to whether LSTs evolve as fully developed neoplastic lesions from the start, or progress through the lateral extension of pre-existing FAs. In this context, Sato et al. followed-up 14 patients with flat colonic tumors with colonoscopy for 19 months (range=11- 
Table I. The frequency of predominant histological phenotypes in crypts with normal epithelial lining but with corrupted shapes (NECS), found beneath the neoplastic canopy in 51 non-polypoid colon adenomas: 27 flat adenomas (FA), and 24 lateral-spreading adenomas (LSA).

\begin{tabular}{lccc}
\hline $\begin{array}{l}\text { Predominant NECS } \\
\text { phenotype }\end{array}$ & $\begin{array}{c}\text { FA, } \\
\mathrm{n}(\%)\end{array}$ & $\begin{array}{c}\text { LSA, } \\
\mathrm{n}(\%)\end{array}$ & $\begin{array}{c}\text { Overall, } \\
\mathrm{n}(\%)\end{array}$ \\
\hline Cystic & $10(37 \%)$ & $9(38 \%)$ & $19(37 \%)$ \\
Multilobular & $8(30 \%)$ & $7(29 \%)$ & $15(29 \%)$ \\
Asymmetric fission & $7(26 \%)$ & $6(25 \%)$ & $13(25 \%)$ \\
Axial polarity distortions & $2(7 \%)$ & $2(8 \%)$ & $4(8 \%)$ \\
Total & $27(100 \%)$ & $24(100 \%)$ & $51(100 \%)$ \\
\hline
\end{tabular}

26 months). During that time interval, none of the flat tumors measuring approximately $5 \mathrm{~mm}$ in diameter progressed to LSTs (13). Nevertheless, whether LSTs progress through the lateral extension of pre-existing FAs remains unsettled.

In previous studies, we found colonic crypts with normal epithelial lining, albeit with corrupted shapes (NECS), beneath the adenomatous tissue of polypoid conventional adenomas, in both rats (14) and humans (15). More recently, we noticed in a clinical study NECS beneath the adenomatous tissue of FAs and LSTs. The pertinent question was: Could differences in frequency of NECs or in their histologicat phenotype be of help in discriminating between FAs and LSTs?

Against that background, we explored the frequency and the histological phenotypes of NECS in a cohort of patients with FAs and LSAs.

\section{Materials and Methods}

The study material consisted of sections from 51 endoscopically removed non-polypoid FAs and non-polypoid LSAs. Archival hematoxylin and eosin (H\&E)-stained sections (4- $\mu$ m thick) were retrieved from the files of the Gastrointestinal Research Laboratory of the Department of Pathology, Karolinska University Hospital. This study was approved by The Regional Ethical Review Board in Stockholm (no. 2018/688-32).

Recording the size of sections in FA and LSA. The size of FAs and LSAs was assessed using a standard light Nikon microscope (Nikon Instruments Europe B.V, Amsterdam, the Netherlands), using 10x oculars and a $2 \times$ Plan Apo objective (aperture 0.1). At that magnification, the entire field of view (FOV) was $10 \mathrm{~mm}$ in diameter. Nonpolypoid adenomas restricted to the boundaries of the FOV were recorded as FAs and those exceeding that limit as LSAs.

NECS were defined as crypts with normal epithelial lining albeit with corrupted shapes found below the adenomatous tissue of FAs and LSAs.

Calculation of the NECS/size ratio of FAs and LSAs. The number of NECS found beneath the neoplastic glands of each FA and LSA was divided by the length $(\mathrm{mm})$ of the FA and LSA was calculated.
Table II. The size and number of crypts with normal epithelium but with corrupted shapes (NECS) found beneath the adenomatous tissue, and the NECS/size ratio in 27 flat adenomas (FA) and in 24 lateral spreading adenomas (LSA).

\begin{tabular}{|c|c|c|c|c|c|c|}
\hline \multirow[b]{2}{*}{$\begin{array}{l}\text { Sample } \\
\text { no. }\end{array}$} & \multicolumn{3}{|c|}{ FA } & \multicolumn{3}{|c|}{ LSA } \\
\hline & $\begin{array}{l}\text { Size } \\
(\mathrm{mm})\end{array}$ & $\begin{array}{l}\text { No. of } \\
\text { NECS }\end{array}$ & $\begin{array}{c}\text { Ratio } \\
\text { NECS/size }\end{array}$ & $\begin{array}{l}\text { Size } \\
(\mathrm{mm})\end{array}$ & $\begin{array}{l}\text { No. of } \\
\text { NECS }\end{array}$ & $\begin{array}{c}\text { Ratio } \\
\text { NECS/size }\end{array}$ \\
\hline 1 & 4 & 4 & 1.00 & 19 & 8 & 0.42 \\
\hline 2 & 9 & 9 & 1.00 & 15 & 40 & 2.66 \\
\hline 3 & 6 & 7 & 1.16 & 24 & 12 & 0.50 \\
\hline 4 & 7 & 6 & 0.85 & 20 & 22 & 1.10 \\
\hline 5 & 8 & 10 & 1.25 & 16 & 17 & 1.06 \\
\hline 6 & 7 & 7 & 1.00 & 14 & 9 & 0.64 \\
\hline 7 & 2 & 3 & 1.50 & 17 & 7 & 0.41 \\
\hline 8 & 3 & 4 & 1.33 & 35 & 14 & 0.40 \\
\hline 9 & 7 & 7 & 1.00 & 14 & 10 & 0.71 \\
\hline 10 & 3 & 4 & 1.33 & 12 & 7 & 0.58 \\
\hline 11 & 9 & 5 & 0.55 & 20 & 14 & 0.70 \\
\hline 12 & 8 & 5 & 0.63 & 25 & 26 & 1.04 \\
\hline 13 & 4 & 2 & 0.50 & 25 & 14 & 0.56 \\
\hline 14 & 3 & 2 & 0.66 & 11 & 12 & 1.09 \\
\hline 15 & 4 & 4 & 1.00 & 12 & 8 & 0.66 \\
\hline 16 & 2 & 4 & 2.00 & 13 & 9 & 0.69 \\
\hline 17 & 9 & 5 & 0.55 & 12 & 10 & 0.83 \\
\hline 18 & 8 & 10 & 1.25 & 13 & 11 & 0.84 \\
\hline 19 & 3 & 2 & 0.66 & 15 & 9 & 0.60 \\
\hline 20 & 9 & 6 & 0.66 & 22 & 26 & 1.18 \\
\hline 21 & 9 & 6 & 0.66 & 14 & 41 & 2.93 \\
\hline 22 & 8 & 10 & 1.25 & 17 & 22 & 1.29 \\
\hline 23 & 3 & 2 & 0.66 & 18 & 8 & 0.44 \\
\hline 24 & 9 & 6 & 0.66 & 14 & 10 & 0.71 \\
\hline 25 & 8 & 4 & 0.50 & & & \\
\hline 26 & 9 & 6 & 0.66 & & & \\
\hline 27 & 9 & 9 & 1.00 & & & \\
\hline Total & 149 & 170 & 25.27 & 417 & 367 & 22.11 \\
\hline Mean & 5.52 & 6.29 & 0.94 & 17.34 & 15.29 & 0.92 \\
\hline Range & $2-9$ & $2-10$ & $0.50-2.00$ & $11-35$ & $7-41$ & $0.40-2.93$ \\
\hline
\end{tabular}

Statistical analysis. The non-parametric Kruskal-Wallis test was applied to compare difference between groups. Statistical significance was defined as $p<0.05$.

\section{Results}

Out of the 51 nonpolypoid adenomas, 27 were FAs (Figures 1 and 2) and the remaining 24 were LSAs (Figures 2 and 3). All 51 nonpolypoid adenomas were tubular adenomas.

Histologic NECS phenotypes in FAs and LSAs. The following NECS phenotypes were found: i) Cystic NECS, crypts with a width of more than twice the width of a normal crypt; ii) Multi-lobular NECS, wide NECS displaying several lobules; iii) NECS with asymmetric fission; and iv) NECS with axialpolarity distortions, with oblique or horizontal positions. 

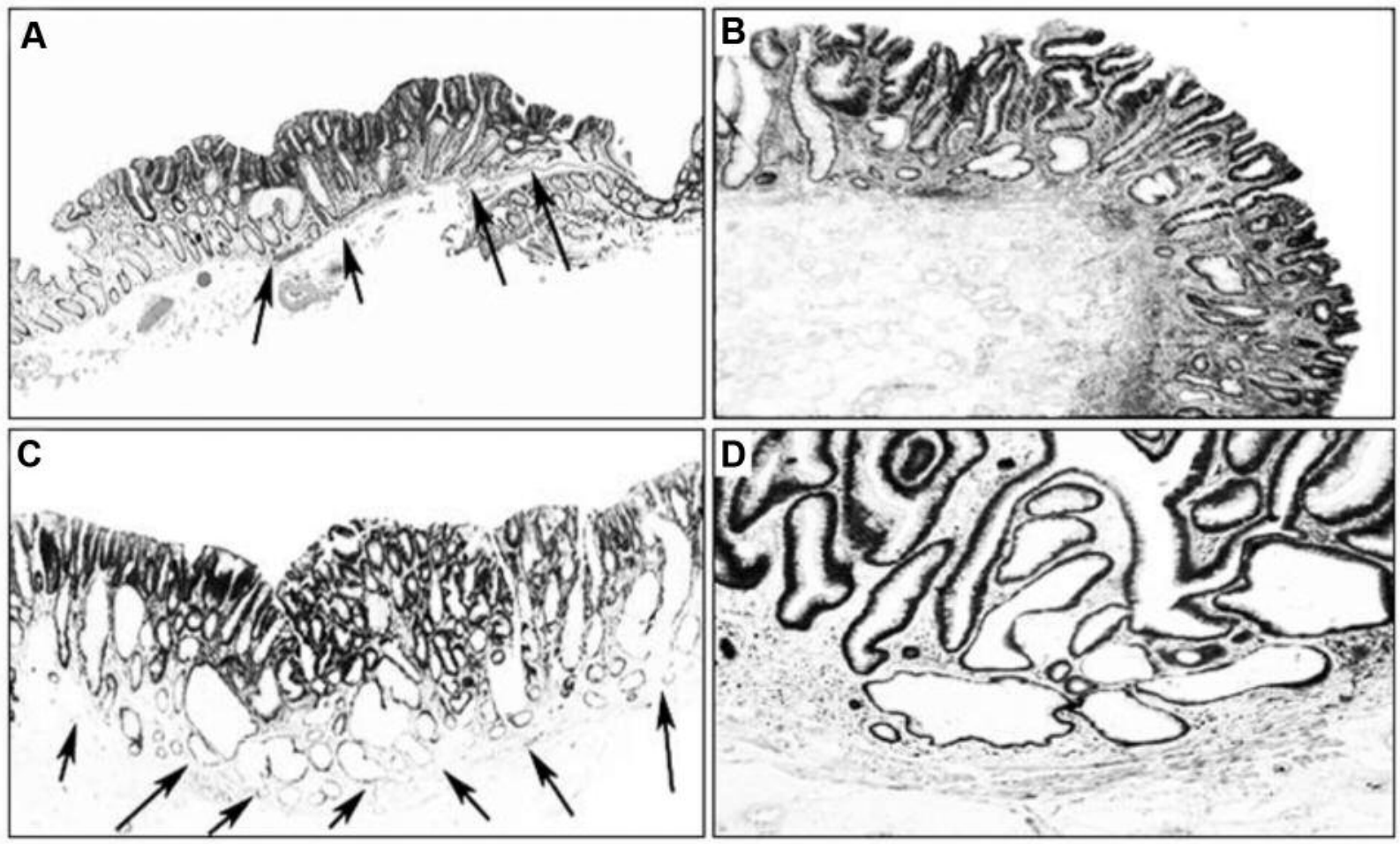

Figure 1. A: Flat adenoma of the colon. Note crypts with abnormal shapes (arrows) located below the darker adenomatous tissue on top (hematoxylin and eosin, $\times 2$ ). B: View of another flat adenoma of the colon showing crypts with corrupted shapes (hematoxylin and eosin, $\times 4$ ). C: Flat adenoma of the colon exhibiting multiple crypts with corrupted shapes indicated by arrows (hematoxylin and eosin, $\times 4$ ). Note the absence of normal-shaped crypts below the darker adenomatous tissue on top. D: A closer view of a flat adenoma of the colon displaying multiple crypts with normal epithelium but with corrupted shapes below the darker adenomatous tissue on top (hematoxylin and eosin, $\times 2$ ).

FAs and LSAs having two or more NECS phenotypes coexisting beneath the adenomatous tissue were classified according to the predominant phenotype recorded.

The results in Table I show that the most frequent predominant phenotype was cystic NECS (37\%), followed by multi-lobular NECS (29\%), NECS with asymmetric fission $(25 \%)$, and finally by NECS with axial polarity distortions (8\%). The difference between the frequency of NECS of the first three phenotypes and NECS with distortions of axial polarity was significant $(p<0.05)$. On the other hand, the difference in the frequency of the NECS phenotypes between FAs and LSAs was non-significant $(p=0.12)$.

Frequency of NECS in FAs and LSAs. Table II shows that the mean number of NECS in the 27 FAs was 6.29 (range=2-10) and in the 24 LSAs was 15.29 (range=7-41). The difference in the number of NECS between FAs and LSAs was significant $(p<0.05)$.

Size of FAs and LSAs. Table II shows that the mean size of FAs was $5.52 \mathrm{~mm}$ (range $=2-9 \mathrm{~mm}$ ), and of LSAs was 17.34 $\mathrm{mm}$ (range $=11-35 \mathrm{~mm}$ ). The difference in size between FAs and LSAs was significant $(p<0.05)$.

The NECS/mm ratio in FAs and in LSAs. Table II also shows that the mean NECS $/ \mathrm{mm}$ ratio for FAs was 0.94 (range $=0.50$ 2.00), and for LSAs was 0.92 (range $=0.40-2.93$ ). Thus, no essential difference was found in the NECS/mm ratio between FAs and LSAs.

\section{Discussion}

The present survey showed that FAs and LSAs differed not only in size, but also in the number of NECS. But when the number of NECS was divided by the size of individual lesions, the resulting NECS/mm ratio showed no essential differences between FAs and LSAs. It would appear that NECS develop independently of the length of the neoplastic tissue in FAs and LSAs.

The accretion of NECS below the neoplastic canopy of FAs and LSAs, contrasts with the very rare occurrence of NECS in normal colonic mucosa (16-19). In this regard, a recent review of normal mucosa revealed that only three out of 22 

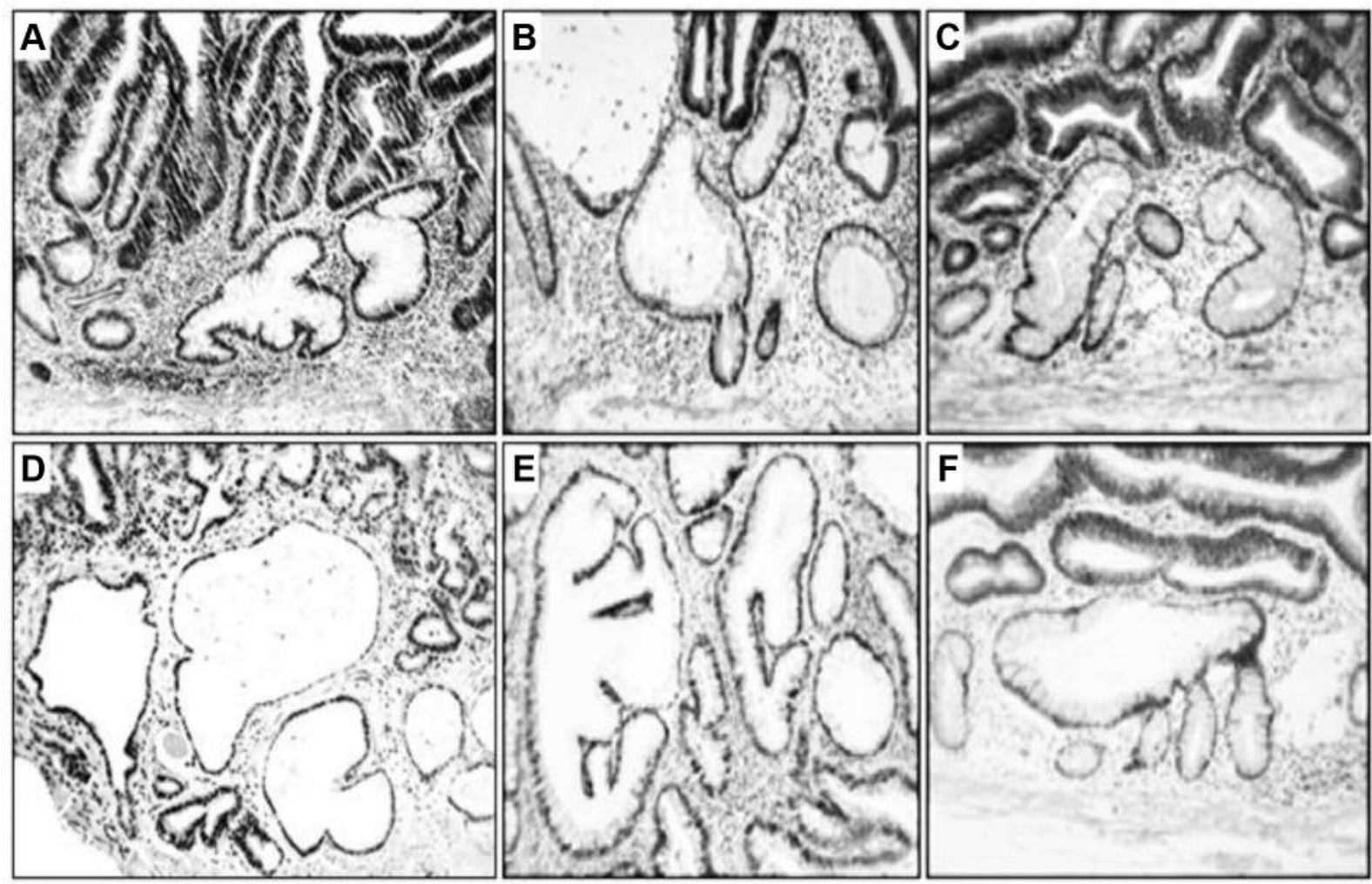

Figure 2. A to F: Magnified views demonstrating crypts with corrupted shapes lined with normal epithelium, found below the adenomatous tissue of flat adenomas of the colon $(A, B$ and $C)$, and below the adenomatous tissue of lateral spreading adenomas of the colon $(D, E$ and $F)($ hematoxylin and eosin, $\times 10$ ).

colonic segments proximal or distal to surgically removed colon cancer in patients had occasional NECS (mean $=3.7$ NECS, range=2-5) (15). Thus, despite the majority of the crypts in those colonic segments being histologically normal, occasional NECS were infrequently seen. Considering that in humans normal colonic crypts typically divide at most once or twice during a lifetime, with an average crypt cycle length of 36 years (20), the finding that NECS frequently evolve underneath the neoplastic canopy of FAs and LSAs emerges as a significant histological event that might play an important role in the histogenesis of FAs and LSAs.

In a preliminary study, we found NECS with asymmetric and haphazardly distributed clusters of cell proliferation underneath conventional adenomas (21). That abnormal distribution of proliferating cells contrasts with that in the normal colon, where proliferating cells are symmetrically aligned in 'Indian files' along both slopes of the lower third of the crypts (22). The abnormal distribution of proliferating cells in NECS (21) suggests that their apparently 'normal' epithelium might harbor putative somatic mutations. Whether similar alterations in cell proliferation occur in NECS present in LA and LSAs, remains to be elucidated.
It should be stressed that not all crypts with corrupted shapes underneath the neoplastic canopy of FAs and LSAs were lined with normal epithelium. A closer examination revealed the presence of interspersed crypts with corrupted shapes, lined with dysplastic epithelium. This finding suggests that NECS acted as scaffold-templates during the well-known top-down replacement of the crypts by the dysplastic epithelium (14, 15, 23, 24). This mechanism rationally masked many NECS.

Park et al. demonstrated in mice that crypts clonally multiply through crypt fission when mutated at the glucose-6-phosphate dehydrogenase (G6PD) locus, and postulated that tumor initiation depended on a high fission rate of mutated crypts (16). Accordingly, the accumulation of crypts underneath the adenomatous glands of FAs and LSAs reported here might have been encouraged by crypt mutations at the G6PD locus.

The crucial question is: What are the morphogenetic mechanisms that trigger colonic crypts lined with normal epithelium to develop corrupted shapes beneath FAs and LSAs?

According to Jagan et al., morphogenesis is the ability of a system to change its form. These authors demonstrated that the formation of a colorectal crypt in humans is regulated by phosphatase and tensin homologue deleted on chromosome 10 (PTEN), a protein encoded by the PTEN gene (25). 

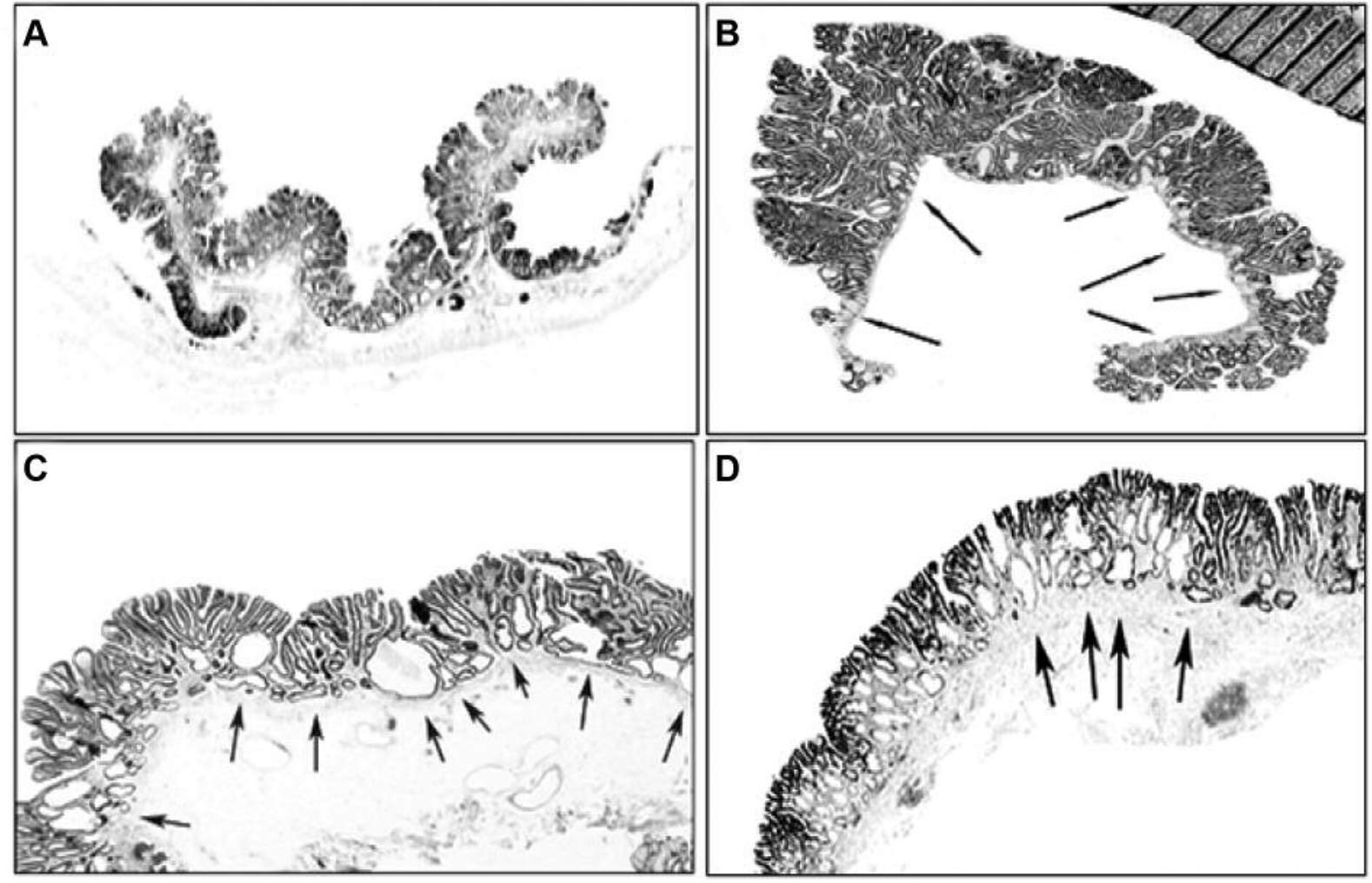

Figure 3. A: Lateral spreading adenoma of the colon (hematoxylin and eosin, $\times 1$ ). B: View of another lateral spreading adenoma of the colon showing multiple dilated crypts with abnormal shapes (arrows) located below the darker adenomatous tissue on top (hematoxylin and eosin, $\times 2$ ). $C$ : Magnified view of a lateral spreading adenoma of the colon. Note crypts with abnormal shapes (arrows) located below the darker adenomatous tissue on top (hematoxylin and eosin, $\times 4$ ). D: View of another lateral spreading adenoma of the colon showing crypts with abnormal shapes (arrows) located below the darker adenomatous tissue on top (immunostained for the proliferative marker Ki-67, $\times 4$ ).

Subsequently, in three-dimensional (3D) studies of human colon crypts, Georgescu et al. found that $\mathrm{Na}^{+} / \mathrm{H}^{+}$exchanger regulatory factor NHERF1 controls gland morphogenesis (26). Thus, the NECS found beneath the adenomatous tissue of FAs and LSAs might have been generated by aberrations in NHERF1 and PTEN morphogenesis signaling (26).

In 1963, Cole and McKalen postulated that the stem cells that trigger the development of polypoid adenomas of the colon might be located between the crypt orifices and not at the base of the crypts (27). But in the same year, Lane and Lev put forward the possibility that at the base of the adenomatous crypts, the normal-looking epithelium might have been transformed and that the dysplastic epithelium on top might only be demonstrated as the cells began to differentiate and migrate up the crypt column (28).

The question arises: Which develops first, the adenomatous tissue in FAs and LSAs or the underlying NECS? In an attempt to answer these questions, three options were considered: i) That molecular signals emanating from the adenomatous tissue in FAs and LSAs orchestrate the development of NECS below; ii) that interdependent (symbiotic) cross-talk molecular signals are necessary for the simultaneous evolution of the adenomatous tissue on top and of the NECS below; or iii) that independently of the adenomatous tissue on top, NECS evolve at particular mucosal sites.

From these options, a possible candidate emerges, namely that NECS evolve independently of the adenomatous tissue on top, for the following reasons: NECS were occasionally found in the non-dysplastic mucosa adjacent to FAs and LSAs. The absence of adenomatous tissue on top of NECS should rule out the possibility that the neoplastic tissue was responsible for the development of NECS.

Previous studies on conventional adenomas showed that the mucosa of the stalk (15) also exhibits NECS without adenomatous tissue on top, suggesting that neoplastic epithelium was not a prerequisite for the evolution of NECS in adenomas.

The dysplastic epithelium in FAs and LSAs apparently replaced pre-existing NECS, resulting in interspersed crypts with dysplastic epithelium with corrupted shapes. This finding substantiates the dysplastic epithelium-top-down replacement theory proposed for polypoid adenomas of the colon and rectum $(23,24)$. 
Swiss-rolled colectomies from 35 rats without carcinoma (despite treatment with the colonotropic carcinogen 1,2dimethyhydrazine) revealed four conventional adenomas (14). Below these adenomas, corrupted crypts lined either with non-dysplastic (indigenous) epithelium (NECS) or with dysplastic epithelium with corrupted shapes were found (14).

In conclusion, we demonstrated that NECS accrue under the adenomatous canopy of FAs and LSAs, a phenomenon rarely found in crypts from normal colonic mucosa. The accretion of NECS beneath FAs and LSAs emerges as a previously unaddressed major event, an event that might play an important role in the histogenesis of non-polypoid adenomas of the colon.

\section{References}

1 Muto T, Kamiya J, Sawada T, Konishi F, Sugihara K, Kubota Y, Adachi M, Agawa S, Saito Y, and Morioka Y: Small "flat adenoma" of the large bowel with special reference to its clinicopathologic features. Dis Colon Rectum 28: 847-851, 1985.

2 Jaramillo E, Watanabe M, Slezak P and Rubio C. A: Flat neoplastic lesions of the colon and rectum detected by highresolution video endoscopy and chromoscopy. Gastrointest Endosc 42: 114-122, 1995.

3 Yamada T, Tamura S, Onishi S, and Hiroi M: A comparison of magnifying chromoendoscopy versus histopathology of forceps biopsy specimen in the diagnosis of minute flat adenoma of the colon. Dig Dis Sci 54: 2002-2008, 2009.

4 Rubio CA, Saito Y, Watanabe M, Koizumi K, Takahama KK, Hirata I, Nakano H, Jaramillo E, Slezak P, Kumagai J, Nakamura $\mathrm{K}$, Yanagisawa A, Kato Y, Kawaguchi M, Miyaoka M, Horimukai H, Taguchi Y, Katayama A, Hirota T, Watanabe, Masaki T and Muto T: Non-polypoid colorectal neoplasias: A multicentric study. Anticancer Res 19: 2361-2364, 1999.

5 Church JM, Muto T and Appau K: Flat lesions of the colorectal mucosa: differences in recognition between Japanese and American endoscopists. Dis Colon Rectum 47: 1462-1466, 2004.

6 Kudo S: Flat and depressed types of early colorectal cancers: From East to West. Gastrointest Endoscopy Clin N Am 18: 581593, 2008.

7 Schlemper RJ, Riddell RH, Kato Y, Borchard F, Cooper HS, Dawsey SM, Dixon MF, Fenoglio-Preiser CM, Fléjou JF, Geboes K, Hattori T, Hirota T, Itabashi M, Iwafuchi M, Iwashita A, Kim YI, Kirchner T, Klimpfinger M, Koike M, Lauwers GY, Lewin KJ, Oberhuber G, Offner F, Price AB, Rubio CA, Shimizu M, Shimoda T, Sipponen P, Solcia E, Stolte M, Watanabe $\mathrm{H}$, and Yamabe $\mathrm{H}$ : The Vienna classification of gastrointestinal epithelial neoplasia. Gut 47: 251-255, 2000.

8 Gotoda: Endoscopic resection for premalignant and malignant lesions of the gastrointestinal tract from the esophagus to the colon. Gastrointest Endoscopy Clin N Am 18: 435-450, 2008

9 Kudo S, Kashida H, Nakajima T, Tamura S and Nakajo K: Endoscopic diagnosis and treatment of early colorectal cancer. World J Surg 21: 694-701, 1997.

$10 \mathrm{Kim} \mathrm{HH}$, Kim JH, Park SJ, Park MI and Moon W: Risk factors for incomplete resection and complications in endoscopic mucosal resection for lateral spreading tumors. Dig Endosc 24: 259-266, 2012.

11 Zhao X, Zhan Q, Xiang L, Wang Y, Wang X, Li A and Liu S: Clinicopathological characteristics of laterally spreading colorectal tumor. PLoS One 21: e94552, 2014.
12 Tang XW, Ren YT, Zhou JQ, Wei ZJ, Chen Z, Jiang B and Gong W: Endoscopic submucosal dissection for laterally spreading tumors in the rectum $\geq 40 \mathrm{~mm}$. Tech Coloproctol 20: 437-443, 2016.

13 Sato T, Konishi F, Togashi K, Ozawa A and Kanazawa K: Prospective observation of small "flat" tumors in the colon through colonoscopy. Dis Colon Rectum 42: 1457-1463, 1999.

14 Rubio CA: Corrupted colonic crypt fission in carcinogen-treated rats. PLoS One 12: e0172824, 2017.

15 Rubio CA and Schmidt PT: Are non-dysplastic corrupted colonic crypts the initial recordable histological event in the development of conventional adenomas? Anticancer Res 38: 5315-5320, 2018.

16 Park HS, Goodlad RA and Wright NA: Crypt fission in the small intestine and colon. A mechanism for the emergence of G6PD locus-mutated crypts after treatment with mutagens. Am J Pathol 147: 1416-1427, 1995.

17 Levine DS and Haggitt RC: Normal histology of the colon. Amer J Surg Pathol 13: 966-984, 1989.

18 Dahl J and Greenson JK: Chapter 25: Colon. In: Histology for Pathologists. Mills SE (eds). Lippincott Williams \& Wilkins. Third Edition, Philadelphia, PA, USA, pp. 629-630, 2007.

19 Rubio CA: The histologic structure of the large bowel mucosa and the evolution of the three pathways of colonic carcinogenesis in humans and in experimental animals. In: Recent Studies on Digestive System Anatomy, e-book, 3: 1-12, 2018. http://openaccessebooks.com/digestive-system-anatomy.html.

20 Baker AM, Cereser B, Melton S, Fletcher AG, Rodriguez-Justo M, Tadrous PJ, Humphries A, Elia G, McDonald SA, Wright NA, Simons BD, Jansen M and Graham TA: Quantification of crypt and stem cell evolution in the normal and neoplastic human colon. Cell Rep 8: 940-947, 2014.

21 Rubio CA: Preliminary report: Multiple clusters of proliferating cells in non-dysplastic corrupted colonic crypts underneath conventional adenomas. In Vivo 32: 1473-1475, 2018.

22 Deschner EE: Cell proliferation and colonic neoplasia. Scand J Gastroenterol 151: 94-97, 1988.

23 Shih IM, Wang TL, Traverso G, Romans K, Hamilton SR, BenSasson S, Kinzler KW and Vogelstein B: Top-down morphogenesis of colorectal tumors. Proc Natl Acad Sci USA 98: 2640-2645, 2001.

24 Wright NA and Poulsom R: Top down or bottom up? Competing management structures in the morphogenesis of colorectal neoplasms. Gut 51: 306-308, 2002.

25 Jagan IC, Deevi RK, Fatehullah A, Topley R, Eves J, Stevenson M, Loughrey M, Arthur K and Campbell FC: PTEN phosphataseindependent maintenance of glandular morphology in a predictive colorectal cancer model system Neoplasia 15: 1218-1230, 2013.

26 Georgescu MM, Cote G, Agarwal NK and White CL: NHERF1/EBP50 controls morphogenesis of 3D colonic glands by stabilizing PTEN and ezrin-radixin-moesin proteins at the apical membrane. Neoplasia 16: 365-374, 2014.

27 Cole JW and McKalen A: Studies on the morphogenesis of adenomatous polyps in the human colon. Cancer 16: 998-1002, 1963.

28 Lane $\mathrm{N}$ and Lev R: Observations on the origin of adenomatous epithelium of the colon. Serial section of minute polyps in familial polyposis. Cancer 16: 751-754, 1963.

Received December 8, 2018

Revised December 14, 2018

Accepted December 18, 2018 